\title{
The minimum effective intravenous dose of ondansetron for prevention of postoperative nausea and vomiting after adenotonsillectomy in dexamethasone pretreated children
}

\author{
Asharf Mahmood A. Swellam and Tarek Ali Helal* \\ Assistant Professor - Anesthesia Department, Ain-Shams University, Cairo, Egypt \\ * Assistant Professor - E.N.T Department, Cairo University, Egypt
}

\begin{abstract}
Postoperative nausea and vomiting (PONV) remains a distressing and common problem after tonsillectomy with an incidence ranging from $40-73 \%$ in those who did not receive prophylactic antiemetic. This study was done to identify the minimum effective IV dose of ondansetron to decrease the incidence and severity of PONV in the dexamethasone $(150 \mathrm{ug} / \mathrm{kg})$ pretreated children undergoing adenotonsillectomy. In this prospective, randomized, doubleblinded, placebo-controlled study, 150 children (3-12 years old) received dexamethasone $150 \mu \mathrm{g} / \mathrm{kg}$ IV (maximum $8 \mathrm{mg}$ ) premedication were randomly assigned to receive either placebo (saline) or ondansetron in a dose of $25,50,75$ or $150 \mu \mathrm{g} / \mathrm{kg}$ IV immediately after induction of anesthesia. All children received standardized perioperative care, including surgical and anesthetic techniques, IV fluid, postoperative analgesic and rescue antiemetic (RAE). The incidence and severity of PONV were recorded in a standardized fashion at the intervals 0-2, 212 and $12-24 \mathrm{~h}$ postoperatively. The time to first postoperative analgesic, total analgesic consumptions, the need for rescue antiemetic (RAE), the fast tracking time (FTT), the time to first oral intake and parent's satisfaction score were recorded as clinically true outcome measures. The five treatment groups were similar with respect to patients's characteristics and operative data. There was no significant difference with respect to the incidence $(\mathrm{P}>0.05)$ or severity $(\mathrm{P}>0.05)$ of $\mathrm{PONV}$ between the placebo and $25 \mu \mathrm{g} / \mathrm{kg}$ ondansetron group during the study period (0-24h). The incidence of early $(0-2 \mathrm{~h})$, delayed $(2-12 \mathrm{~h})$, and late (12-24) PONV were significantly less in the $50(\mathrm{P}<0.05), 75(\mathrm{P}<0.05)$ and $150(\mathrm{P}<0.05) \mu \mathrm{g} / \mathrm{kg}$ ondansetron groups compared with placebo. The incidence of $24 \mathrm{~h}$ PONV was $43,37,13,10$ and $7 \%$ in placebo, 25, 50, 75 and $150 \mu \mathrm{g} / \mathrm{kg}$ ondansetron groups, respectively. The PONV severity scores $(0-3)$ were significantly less $(\mathrm{p}<0.05)$ in children who received ondansetron in a dose of $50 \mu \mathrm{g} / \mathrm{kg}$ or more compared with the placebo. There was no statistically significant difference with respect to the incidence $(\mathrm{P}>0.05)$ or the severity $(\mathrm{P}>0.05)$ of PONV between the 50, 75 and $150 \mu \mathrm{g} / \mathrm{kg}$ ondansetron groups. The time to first postoperative analgesic, the total postoperative analgesic consumptions, the need for RAE, the time to first oral intake and the fast tracking time (FTT) were significantly less $(\mathrm{P}<0.05)$ in children who received 50,75 and $150 \mu \mathrm{g} / \mathrm{kg}$ ondansetron in comparison with placebo. The parent's satisfaction scores were significantly high $(\mathrm{P}<0.05)$ for those children who received ondansetron in a doses of $50 \mu \mathrm{g} / \mathrm{kg}$ or more compared with placebo. There was no significant difference with respect to the clinically true outcome measures in children who received ondansetron in dose of $50 \mu \mathrm{g} / \mathrm{kg}$ or more. In conclusion, ondansetron $50 \mu \mathrm{g} / \mathrm{kg}$ IV was the minimum effective IV dose to decrease the incidence and severity of PONV in dexamethasone $(150 \mu \mathrm{g} / \mathrm{kg}$ IV) pretreated children undergoing adenotonsillectomy. This dose was associated with a significant reduction in the time to first postoperative analgesic, total analgesic consumptions, the need for rescue antiemetic (RAE), the time to first oral intake, the fast tracking time (FTT) and a high parent's satisfaction scores. Increasing the dose of ondansetron to $150 \mu \mathrm{g} / \mathrm{kg}$ provided no significant benefits in reducing the incidence or severity of PONV in dexamethasone $(150 \mu \mathrm{g} / \mathrm{kg}$ IV) pretreated children undergoing adenotonsillectomy.
\end{abstract}




\section{Introduction}

Tonsillectomy with or without adenoidectomy is one of the most frequently performed surgical procedure in children and is associated with an incidence of postoperative nausea and vomiting (PONV) ranging between $40-73 \%$. Thus, prophylactic antiemetic therapy is highly indicated in this high risk group of children ${ }^{1}$.

Dexamethasone has been reported to be an effective, low cost and long lasting prophylactic antiemetic for prevention of PONV in children undergoing ambulatory adenotonsillectomy ${ }^{2-5}$. Also, it has combined analgesic and anti-inflammatory effects that may decrease postoperative edema and subsequently may improve oral intake after adenotonsillectomy ${ }^{6,7}$.

Previous studies on ondansetron antiemetic potential in children have produced conflict results ${ }^{8-13}$. Different single IV doses of ondansetron have been used to decrease the incidence of PONV in children undergoing tonsillectomy ${ }^{\mathbf{8}-12}$. The combination of dexamethasone with ondansetron is likely to be the most effective prophylactic antiemetic intervention currently available for the control of PONV after tonsillectomy ${ }^{\mathbf{1 3}}$. The dose effectiveeness of intravenous ondansetron when used as a prophylactic antiemetic for prevention of PONV in dexamethasone pretreated children undergoing tonsillectomy is not well defined. Moreover, a number of studies and meta-analysis that evaluated the effects of ondansetron on PONV reported non-clinically true outcome measures, such as the incidence of PONV and the number of emetic episodes per patient, rather than more clinically important true outcome measures, such or fast tracking time (FTT), parent's satisfaction score and hospital readmission ${ }^{14}$.

The aim of this study was to evaluate the effects of four different single IV doses of ondansetron $(25,50,75$ and $150 \mu \mathrm{g} / \mathrm{kg})$ on the incidence and severity of PONV in dexamethasone $(150 \mu \mathrm{g} / \mathrm{kglV})$ pretreated children scheduled for electro-dissection adenotonsillectomy under general anesth- esia. The second objective was to specify the safety and clinical effectiveness of these 4 different doses with clinically true outcome measures such as the time to first postoperative analgesic, total analgesic consumptions, the need for rescue antiemetic (RAE), the time to first oral intake, the fast tracking time (FTT) ), and parent's satisfaction scores.

\section{Patients and Methods}

After obtaining hospital review board approval and written informed parent consent, 150 children, 3-12 yr of age, American Society of Anesthesiologist (ASA) physical status I or II, scheduled for adenotonsillectomy were enrolled in this prospective, randomized, double-blinded, placebo-controlled study. Children who had received antiemetics, antihistaminics, steroids or psychoactive drugs within $24 \mathrm{~h}$ of surgery were excluded. Children with a history of an adverse drug reaction to any of the medications used in the anesthetic management outlined below were not eligible to participate in this study. Children did not consume milk or solid food for at least $6 \mathrm{~h}$ before operation; clear fluids were allowed until $3 \mathrm{~h}$ before induction.

Children were not premedicated. Intravenous (IV) line was established and all children received fentanyl $1 \mu \mathrm{g} / \mathrm{kg}$ IV and dexamethasone $150 \mu \mathrm{g} / \mathrm{kg}$ IV (maximum dose 8mg). Anesthesia was induced with sevoflurane $8 \%$ end-inspired concentration and $50 \%$ nitrous oxide in oxygen via a face mask. Patients $>8 \mathrm{yr}$ of age had IV induction with propofol $2 \mathrm{mg} / \mathrm{kg}$. After induction of anesthesia, patients were randomly assigned to 5 equal groups (30 patients each) by a computer-generated random number-table to receive a single IV dose of either saline (placebo) or ondansetron $25,50,75$ or $150 \mu \mathrm{g} / \mathrm{kg}$. The study medications were prepared, by an anesthesiologist who was not involved in any subsequent assessment to a fixed volume of $2 \mathrm{ml}$ in identical syringes 
(ondansetron and saline were indistinguishable in appearance) to maintain the double-blind nature of the study. Tracheal intubation was facilitated by mivacurium $(0.3 \mathrm{mg} / \mathrm{kg})$. Anesthesia was maintained with sevoflurane $1-5 \%$ endinspired concentrations (adjusted to maintain heart rate and blood pressure within $20 \%$ of the baseline value) and 50\% nitrous oxide in oxygen. Ventilation was mechanically controlled and adjusted to maintain end-tidal $\mathrm{CO}_{2}$ value between 30$35 \mathrm{mmHg}$ throughout the surgery. Intraoperotive IV fluid compromised lactated Ringer's solution, replacing half of the fluid deficit plus maintenance fluid. Neuromuscular block was maintained with supplemental mivacurium as clinically indicated. All children received paracetamol $30 \mathrm{mg} / \mathrm{kg}$ rectally approximately 10 min before the end of surgery and repeated every $6 \mathrm{hrs}$ for the first $24 \mathrm{~h}$ postoperatively. Residual neuromuscular blockade was allowed to recover spontaneously in all patients, without pharmacological reverse of the muscle relaxant. Children were tracheally extubated when they had demonstrated satisfactory motor power and wakefulness. After operation, all children were transferred to the postanesthesia care unit (PACU) where standard monitoring was established and children were observed for a period of at least $2 \mathrm{~h}$.

In the PACU, management of IV fluid, postoperative pain and PONV were standardized. Postoperative IV fluid compromised lactated Ringer's solution, replac-ing the remaining of the fluid deficit plus maintenance fluids. Postoperative analgesia (fentanyl $0.5 \mu \mathrm{g} / \mathrm{kg}$ IV) bolus doses were provided if old children reported pain or if young children cried. The time to first dose of fentanyl and the total fentanyl consumptions were recorded. Metoclopramide $150 \mu \mathrm{g} / \mathrm{kg}$ IV was given as rescue antiemetic (RAE) when the child experienced more than $15 \mathrm{~min}$ of nausea, or two emetic episodes. If PONV persisted for 20 minutes after administration of metoclopramide, a second rescue antiemetic consisting of IV droperidol $0.015 \mathrm{mg} / \mathrm{kg}$ (minimum, $0.65 \mathrm{~m}$; maximum $1.25 \mathrm{mg}$ ) was administered. The total number of children who requested for RAE was recorded. Oral fluids were offered and encouraged by the nursing staff during the recovery period to the children. The time to first oral intake and the quality of swallowing were also recorded.

All incidences of PONV in the first 24 postoperative hours at the intervals of $0-2 \mathrm{~h}$ (early PONV), 2-12h (delayed PONV), and 12-24h (late PONV) were recorded. The severity of PONV over the first 24 postoperative hours was assessed using the numeric scoring system for $\mathrm{PONV}^{(\mathbf{1 4})}(0=$ no nausea or vomiting $1=$ nausea but no vomiting, $2=$ vomiting once $3=$ two or more episodes of vomiting).The incidence and severity of PONV were recorded in PACU $(0-2 \mathrm{~h})$ by the anesthesiologist who provided the intraoperative care and by a trained anesthesia nurse in the surgical ward (224h).

Nausea was defined as a subjective feeling of the urge to vomit. Vomiting was defined as the forceful expulsion of gastric contents through the mouth. Vomiting and retching were grouped together under common term "emetic episodes". Episodes of vomiting occurring less than five min. apart were considered one episode. If there were more than 4 episodes of emesis within the $24 \mathrm{~h}$ observation period, the emesis was considered severe. Those children, who had severe PONV (score 3 ) in the first 2 postoperative hours of their PACU stay, were observed in the PACU until they remained PONV free for $1 \mathrm{~h}$.

The time to achieve eligibility for discharge from PACU to the ward (fast tracking time) (FTT) was calculated as the time from the discontinuation of sevoflurane to the time at which the child had a patent airway without assistant, stable vital signs, mild or no PONV, adequate pain control and Aldrete recovery score 9 (score of 0-10: 0, 1 and 2 to activity, respiration, circulation, color and consciousness with score of 9 indicating eligibility for transfer from PACU) ${ }^{15}$.

Finally, at the end of the $24 \mathrm{~h}$ observation period, the primary caretaker was asked to give a global assessment of 
the entire postoperative experience of the child (parent's satisfaction score) using an 11-point verbal numeric scoring system ( $0=$ not at all satisfied, $10=$ full satisfied). The details of any adverse effects through the study period $(0-24 \mathrm{~h})$ such as headache, constipation, or drowsiness were also recorded.

\section{Statistical Analysis}

The previous reported incidence of PONV after adenotonsillectomy in children was ranging between $40 \%$ and $73 \%$ (1). Sample size was determined assuming that the acceptable difference in vomiting is $20 \%$. The alpha error was set at 0.05 , and type II error was set as 0.20 . Therefore, this study was targeted for a sample size of 150 patients (30 in each group). Data were analyzed using one-way analysis of variance with a linear contrast, $\mathrm{X}$ test. Severity of PONV between the ondansetron $25,50,75$, and $150 \mu \mathrm{g} / \mathrm{kg}$ groups and the placebo group was compared by chi-square analysis and the Fisher exact test with a Yates' correction as appropriate. Data were presented as the mean \pm SD or number and percentage. $\mathrm{P}$ value $<0.05$ was considered statistically significant.

\section{Results}

Patient characteristics and operative data such as patient age, gender, weight, ASA physical status, duration of surgery, anesthesia and recovery times, perioperative fluid and number of children induced with propofol were similar among three groups (table 1).

Table (2) represented the incidence of PONV in the first 24 postoperative hours at the intervals of $0-2 \mathrm{~h}$ (early PONV), 2-12h (delayed PONV), and 12- 24h (late PONV). There was no significant difference $(\mathrm{P}>0.05)$ between the placebo and the $25 \mu \mathrm{g}$ ondansetron group with respect to the incidence of PONV at the entire study period. A reduction in the incidence of early $(0-2 \mathrm{~h})$, delayed $(2-12 \mathrm{~h})$ and late (1224h) PONV were observed in the 50
$(\mathrm{P}<0.05), \quad 75 \quad(\mathrm{P}<0.05) \quad$ and $\quad 150 \mu \mathrm{g} / \mathrm{kg}$ $(\mathrm{P}<0.05)$ ondansetron groups compared with placebo. No significant difference $(\mathrm{P}>0.05)$ was recorded as regard to the incidence of PONV between the ondansetron 50,75 and $150 \mu \mathrm{g} / \mathrm{kg}$ groups at all time intervals.

Table (3) represented the PONV severity scores (0-3) in the entire study period $(0-24 \mathrm{~h})$. The episodes of vomiting per child were ranging from $0-5$. There was no significant difference $(\mathrm{P}>0.05)$ between the placebo and the $25 \mu \mathrm{g}$ ondansetron group with respect to PONV severity scores at the entire study period. All PONV severity scores were significant less $(p<0.05)$ in children who had received ondansetron in dose of $50 \mu \mathrm{g} / \mathrm{kg}$ or more compared with the placebo group. There were no significant differences $(\mathrm{P}>0.05)$ with respect to PONV severity scores between the $50 \mu \mathrm{g}, 75$ and $150 \mu \mathrm{g}$ ondansetron groups.

Table (4) represented the clinically true outcome measures in the entire study period $(0-24 \mathrm{~h})$. There was no significant difference in the clinically true outcome measures between children who received $25 / \mu \mathrm{g} / \mathrm{kg}$ ondansetron or placebo. The time to first fentanyl analgesic, the total fentanyl consumptions, number of children requested for RAE, the time to first oral intake and the PACU stay (FTT) were significantly less in children who received 50 $(\mathrm{P}<0.05), \quad 75 \quad(\mathrm{P}<0.05) \quad$ or $150 \quad(\mathrm{P}<0.05)$ $\mu \mathrm{g} / \mathrm{kg}$ ondansetron in comparison with placebo. The parent's satisfaction scores were significantly higher $(\mathrm{P}<0.05)$ for those children who received ondansetron in a doses of $50 \mu \mathrm{g} / \mathrm{kg}$ or more compared with the placebo. There was no significant difference in the clinically true outcome measures between children who received 50,75 or $150 / \mu \mathrm{g} / \mathrm{kg}$ ondansetron.

Children who received ondansetron in a doses of $50 \mu \mathrm{g} / \mathrm{kg}$ or more had statistically significant $(\mathrm{p}<0.05)$ more incidence of drowsiness (table 5). 
Table (1): Patients demographic and Operative Data

\begin{tabular}{|c|c|c|c|c|c|}
\hline \multirow{2}{*}{$\begin{array}{l}\text { Demographic and } \\
\text { Operative Data }\end{array}$} & \multirow{2}{*}{$\begin{array}{l}\text { Placebo } \\
\text { Group }\end{array}$} & \multicolumn{4}{|c|}{ Ondansetron Groups } \\
\hline & & $25 \mu \mathrm{g} / \mathrm{kg}$ & $50 \mu \mathrm{g} / \mathrm{kg}$ & $75 \mu \mathrm{g} / \mathrm{kg}$ & $150 \mu \mathrm{g} / \mathrm{kg}$ \\
\hline No. of patients & 30 & 30 & 30 & 30 & 30 \\
\hline Age $(\mathrm{yr})$ & $6.8 \pm 2.8$ & $6.6 \pm 2.9$ & $6.6 \pm 3.1$ & $6.1 \pm 3.4$ & $6.2 \pm 3.4$ \\
\hline Gender $(\mathrm{M} / \mathrm{F})$ & $15 / 15$ & $16 / 14$ & $13 / 17$ & $14 / 16$ & $14 / 16$ \\
\hline Weight (kg) & $19.4 \pm 8.0$ & $20.5 \pm 8.7$ & $19.5 \pm 7.6$ & $19.3 \pm 10.0$ & $20.6 \pm 10.2$ \\
\hline ASA status I or II & $28 / 2$ & $27 / 3$ & $30 / 0$ & $28 / 2$ & $29 / 1$ \\
\hline Duration of anesthesia (min) & $45.8 \pm 14.6$ & $48.4 \pm 13 / 3$ & $47.4 \pm 12.1$ & $46.2 \pm 14.2$ & $48.4 \pm 13.4$ \\
\hline Duration of surgery (min) & $30.0 \pm 12.7$ & $32.4 \pm 13.4$ & $33.0 \pm 14.4$ & $31.0 \pm 13.0$ & $33.4 \pm 14.0$ \\
\hline Recovery time (min) & $8.7 \pm 14.7$ & $10.3 \pm 15.3$ & $9.7 \pm 11.3$ & $9.4 \pm 10.1$ & $8.2 \pm 9.4$ \\
\hline Perioperative IV fluid(ml/kg) & $17.1 \pm 5.5$ & $18.8 \pm 5.9$ & $16.8 \pm 5.7$ & $15.4 \pm 6.7$ & $16.1 \pm 6.6$ \\
\hline $\begin{array}{l}\text { Children induced } \\
\text { with propofol (N0.) }\end{array}$ & 7 & 5 & 6 & 6 & 7 \\
\hline
\end{tabular}

Age, weight, ASA physical status, anesthetic, surgical and recovery times, perioperative IV fluid were presented as the mean \pm SD. ASA physical status, gender and propofol inductions, were presented as the number of children. The demographic and operative data were comparable in all groups $(\mathrm{p}>0.05)$.

Table (2): Incidence of PONV: Number of Patients (\%)

\begin{tabular}{|l|c|c|c|c|c||}
\hline \multirow{2}{*}{$\begin{array}{l}\text { Incidence of PONV } \\
(\mathbf{0 - 2 4 h})\end{array}$} & \multirow{2}{*}{$\begin{array}{c}\text { Placebo Gr. } \\
(\mathbf{n = 3 0})\end{array}$} & $\begin{array}{c}\mathbf{2 5}(\boldsymbol{\mu g} / \mathbf{k g}) \\
(\mathbf{n = 3 0})\end{array}$ & $\begin{array}{c}\mathbf{5 0}(\boldsymbol{\mu g} / \mathbf{k g}) \\
(\mathbf{n = 3 0})\end{array}$ & $\begin{array}{c}\mathbf{7 5}(\boldsymbol{\mu g} / \mathbf{k g}) \\
(\mathbf{n = 3 0})\end{array}$ & $\begin{array}{c}\mathbf{1 5 0}(\boldsymbol{\mu g} / \mathbf{k g}) \\
(\mathbf{n = 3 0})\end{array}$ \\
\hline 0-2h (early PONV) & $7(23.33)$ & $6(20.00)$ & $4(13.33)^{*}$ & $3(10.00)^{*}$ & $2(6.66)^{*}$ \\
\hline 2-12h (delayed PONV) & $8(26.66)$ & $6(20.00)$ & $3(10.0) *$ & $2(6.66) *$ & $3(10.00)^{*}$ \\
\hline 12-24h (late PONV) & $7(23.33)$ & $6(20.00)$ & $3(10.00)^{*}$ & $3(10.00)^{*}$ & $2(6.66)^{*}$ \\
\hline 0-24h (24h PONV) & $13(43.33)$ & $11(36.66)$ & $4(13.33)^{*}$ & $3(10.00)^{*}$ & $2(6.66)^{*}$ \\
\hline
\end{tabular}

The values were presented as the number of children (\%)

There was no significant difference $(\mathrm{P}>0.05)$ between the placebo and the $25 \mu \mathrm{g}$ ondansetron group with respect to the incidence of PONV at the entire study period (0-24). A reduction in the incidence of early $(0-2 \mathrm{~h})$, delayed $(2-12 \mathrm{~h})$ and late (12-24h) PONV were observed in the 50 $(\mathrm{P}<0.05), 75(\mathrm{P}<0.05)$ and $150 \mu \mathrm{g} / \mathrm{kg}(\mathrm{P}<0.05)$ ondansetron groups compared with placebo group. No significant difference $(\mathrm{P}>0.05)$ was recorded as regard to the incidence of PONV between the ondansetron 50,75 and $150 \mu \mathrm{g} / \mathrm{kg}$ groups at all time intervals.

PONV (postoperative nausea and vomiting)

$*=\mathrm{P}<0.05$ 
Table (3): PONV severity score during the study period $(0-24 h)$

\begin{tabular}{|c|c|c|c|c|c|}
\hline \multirow{2}{*}{$\begin{array}{l}\text { PONV severity } \\
\text { score }(0-3)\end{array}$} & \multirow{2}{*}{$\begin{array}{l}\text { Placebo Gr. } \\
\qquad(\mathbf{n = 3 0})\end{array}$} & \multicolumn{4}{|c|}{ Ondansetron Groups } \\
\hline & & $\begin{array}{c}25(\mu \mathrm{g} / \mathrm{kg}) \\
(\mathrm{n}=30)\end{array}$ & $\begin{array}{c}50(\mu \mathrm{g} / \mathrm{kg}) \\
(\mathrm{n}=30)\end{array}$ & $\begin{array}{c}75(\mu \mathrm{g} / \mathrm{kg}) \\
(\mathrm{n}=30)\end{array}$ & $\begin{array}{c}150(\mu \mathrm{g} / \mathrm{kg}) \\
(\mathrm{n}=30)\end{array}$ \\
\hline 0 (no) & $16(53.33)$ & $14(46.66)$ & $25(83.33)^{*}$ & $26(86.66)^{*}$ & $24(80.00)^{*}$ \\
\hline 1 (mild) & $5(16.66)$ & $6(20.00)$ & $1(3.33)^{*}$ & $2(6.66)^{*}$ & $1(3.33)^{*}$ \\
\hline 2 (moderate) & $4(13.33)$ & $3(10.00)$ & $2(6.66)^{*}$ & $0(0.00)^{*}$ & $2(6.66)^{*}$ \\
\hline 3 (severe) & $7(23.33)$ & $5(16.66)$ & $1(3.33)^{*}$ & $1(3.33)^{*}$ & $2(6.66)^{*}$ \\
\hline
\end{tabular}

The values were presented as the number of children $(\%)$

The episodes of vomiting per child were ranging from 0-5. There was no significant difference $(\mathrm{P}>0.05)$ between the placebo and the $25 \mu \mathrm{g}$ ondansetron group with respect to PONV severity scores at the entire study period. All PONV severity scores were significantly less $(p<0.05)$ in children who had received ondansetron in dose of $50 \mu \mathrm{g} / \mathrm{kg}$ or more compared with the placebo group. There were no significant differences $(\mathrm{P}>0.05)$ with respect to PONV severity scores between the $50 \mu \mathrm{g}, 75$ and $150 \mu \mathrm{g}$ ondansetron groups.

The numeric scoring system for PONV ${ }^{(\mathbf{1 4})}(\mathbf{0}=$ no nausea or vomiting $\mathbf{1}$ = nausea but no vomiting, $\mathbf{2}$ = vomiting once $\mathbf{3}=$ two or more episodes of vomiting).

PONV (postoperative nausea and vomiting).

$*=\mathrm{P}<0.05$

Table (4): The clinically true outcome measurements (0-24h)

\begin{tabular}{|c|c|c|c|c|c|}
\hline & \multirow{2}{*}{ Placebo } & \multicolumn{4}{|c|}{ Ondansetron group } \\
\hline & & $25 \mu \mathrm{g} / \mathrm{kg}$ & $50 \mu \mathrm{g} / \mathrm{kg}$ & $75 \mu \mathrm{g} / \mathrm{kg}$ & $150 \mu \mathrm{g} / \mathrm{kg}$ \\
\hline Time to first dose of fentanyl (min) & $11 \pm 2$ & $13 \pm 3$ & $23 \pm 1 *$ & $21 \pm 4^{*}$ & $22 \pm 2 *$ \\
\hline $\begin{array}{l}\text { Total consumed fentanyl }(\mathrm{mg}) \text { in the } \\
\text { PACU }\end{array}$ & $51 \pm 7$ & $56 \pm 6$ & $25 \pm 9 *$ & $28 \pm 4^{*}$ & $27 \pm 8^{*}$ \\
\hline $\begin{array}{l}\text { Number of children requested for } \\
\text { RAE (No.) }\end{array}$ & 16 & 14 & $6 *$ & $7 *$ & $5^{*}$ \\
\hline $\begin{array}{l}\text { Time to first oral } \\
\text { intake (min) }\end{array}$ & $360 \pm 70$ & $390 \pm 45$ & $183 \pm 27 *$ & $185 \pm 41 *$ & $184 \pm 36^{*}$ \\
\hline PACU stay (FTT) min & $154 \pm 23$ & $157 \pm 36$ & $128 \pm 12 *$ & $127 \pm 12 *$ & $122 \pm 14^{*}$ \\
\hline $\begin{array}{l}\text { Children with good to excellent oral } \\
\text { intake }(\%)\end{array}$ & 45 & 56 & $81 *$ & $86^{*}$ & $84 *$ \\
\hline Parent's satisfaction score $(0-10)$ & $5.7 \pm 1.6$ & $5.8 \pm 1.5$ & $8.7 \pm 1.3^{*}$ & $8.9 \pm 1.6^{*}$ & $8.1 \pm 1.2 *$ \\
\hline
\end{tabular}

Values were expressed as Mean $\pm \mathrm{SD}$, number or $\%$

The time to first postoperative fentanyl analgesia, the total postoperative fentanyl consumptions, number of children who requested for RAE, the time to first oral intake and PACU stay (FTT) were significantly less $(\mathrm{P}<0.05)$ in children who received 50,75 or $150 \mu \mathrm{g} / \mathrm{kg}$ ondansetron in comparison with placebo. The parent's satisfaction scores were significantly higher $(\mathrm{P}<0.05)$ for those children who received ondansetron in a doses of $50 \mu \mathrm{g} / \mathrm{kg}$ or more compared with the placebo. There was no significant difference between children who received 50,75 or $150 / \mu \mathrm{g} / \mathrm{kg}$ ondansetron with respect to the clinically true outcome measures.

PONV $=$ Postoperative nausea and vomiting.

$\mathrm{RAE}=$ Rescue antiemetics.

$* \mathrm{P}<0.05$ 
Table (5): Side effects during the study period $(0-24 \mathrm{~h})$

\begin{tabular}{|c|c|c|c|c|c|}
\hline \multirow{3}{*}{$\begin{array}{l}\text { SIDE } \\
\text { EFFECTS }\end{array}$} & \multirow{3}{*}{$\begin{array}{l}\text { Placebo } \\
\text { Group }\end{array}$} & \multicolumn{4}{|c|}{ Ondansetron Groups } \\
\hline & & $25 \mathrm{mg} / \mathrm{kg}$ & $50 \mathrm{mg} / \mathrm{kg}$ & $75 \mathrm{mg} / \mathrm{kg}$ & $150 \mathrm{mg} / \mathrm{kg}$ \\
\hline & & $(\mathrm{n}=30)$ & $(n=30)$ & $(\mathrm{n}=30)$ & $(n=30)$ \\
\hline Headache & 2 & 2 & 1 & 2 & 2 \\
\hline Constipation & 0 & 0 & 1 & 1 & 2 \\
\hline Drowsiness & 1 & 0 & 0 & $3^{*}$ & $4^{*}$ \\
\hline
\end{tabular}

Values were presented as number of patients

Children who received ondansetron in a doses of $75 \mu \mathrm{g} / \mathrm{kg}$ or more had statistically significant $(\mathrm{p}<0.05)$ more incidence of drowsiness in comparison to placebo.

$*=\mathrm{P}<0.05$

\section{Discussion}

The present study demonstrated that ondansetron $50 \mu \mathrm{g} / \mathrm{kg}$ IV is the minimum effective IV dose to decrease the incidence and severity of PONV in dexamethasone $(150 \mu \mathrm{g} / \mathrm{kg}$ IV) pretreated children undergoing adenotonsillectomy. This dose was associated with reduction of postadenotonsillectomy PONV from $43 \%$ to $13 \%$ in dexamethasone $(150 \mu \mathrm{g} / \mathrm{kg}$ IV $)$ pretreated children. This dose was also associated with a significant reduction in the time to first postoperative analgesic, total analgesic consumptions, the need for rescue antiemetic (RAE), the time to first oral intake, the fast tracking time (FTT) and with high parent's satisfaction scores. Increasing the dose of ondansetron to $150 \mu \mathrm{g} / \mathrm{kg}$ provided no significant benefits in reducing the incidence or severity of PONV after adenotonsillectomy in dexamethasone $(150 \mu \mathrm{g} / \mathrm{kg}$ IV) pretreated children.

Postoperative nausea and vomiting (PONV) not only causes distress to the patient, tension on sutures, and potential bleeding at the operative site, but also may lead to delayed discharge from ambulatory surgical centers, fluid and electrolyte imbalance, and unanticipated hospital admission ${ }^{16}$. Although much attention has been paid to the prevention of PONV during the last decade, the optimal antiemetic regimen for children in the surgical setting has still not been established '. PONV after adenotonsillectomy in children is a complex and multifactorial, such as patient characteristics, operative procedure, anesthetic technique, postoperative pain and perioperative fluid therapy. In the current study, the groups were comparable with respect to patient characteristics, surgical procedure, anesthetic technique, and perioperative analgesics and intravenous fluid. Therefore, the differences in the incidence and severity of PONV and the clinically true outcome measures among the groups in this study can be attributed only to the difference in the dose of ondansetron administered. The four ondansetron doses selected for this study cover the range of preemptive IV ondansetron doses $(25-150 \mu \mathrm{g} / \mathrm{kg})$ that have been evaluated in pediatric surgical sitting ${ }^{8-}$ 14. In this study, high dose of ondansetron $(150 \mu \mathrm{g} / \mathrm{kg})$ was selected because it has been shown that, this dose effectively reduced post tonsillectomy vomiting 8 , ${ }^{9}$.Lowe dose ondansetron $25 \mu \mathrm{g} / \mathrm{kg}$ was selected because there was evidences that this dose may have antiemetic efficacy in pediatric ambulatory surgery ${ }^{14}$.

Several studies have substantiated the efficacy of various antiemetic agents in the treatment of post-tonsillectomy vomiting. Ferrari and Donlon ${ }^{17}$ reduced the incidence of vomiting from $70 \%$ to $47 \%$ by using 
0.15mg. $\mathrm{kg}^{-1}$ metoclopramide. Stene and his colleagues ${ }^{18}$ demonstrated less dramatic results, with higher dose of metoclopramide $\left(0.25 \mathrm{mg} \cdot \mathrm{kg}^{-1)}\right.$ and reported incidences of vomiting 54\% in their treatment group and $69 \%$ in the control group. Sten ${ }^{18}$ and his colleagues also investigated the ondansetron in preventing post-tonsillectomy emesis and reported PONV incidence of $26 \%$. In another study, Litman and his colleagues ${ }^{19}$ demonstrated that $0.15 \mathrm{mg} \cdot \mathrm{kg}^{-1}$ ondansetron reduced the incidence of vomiting from $73 \%$ to $23 \%$. Similar results were obtained by Furst and Rodarte ${ }^{20}$ who reported a decrease in post-tonsillectomy vomiting from $62 \%$ to $27 \%$. In each of these studies, the primary anesthetic agent was either halothane or isoflurane. These studies differed in several aspects: exclusion of patients with a history of motion sickness, use of non-depolarizing muscle relaxants, different opioid analgesic regimens and whether the patient's stomachs were emptied at the conclusion of the procedure. Interestingly, despite the differences in the experimental protocols these studies had similar incidences of vomiting in their control and treatment groups.

The present study demonstrated a decrease in $24 \mathrm{~h}$ post-tonsillectomy PONV from $43 \%$ to $13 \%$ by utilizing ondansetron $50 \mu \mathrm{g} / \mathrm{kg}$ IV in dexamethasone $(150 \mu \mathrm{g} / \mathrm{kg}$ IV) pretreated children. Splinter and Rhine $^{13}$ demonstrated a $30 \%$ incidence of PONV in patients who received ondansetron $50 \mu \mathrm{g} / \mathrm{kg}$ IV plus $150 \mu \mathrm{g} / \mathrm{kg}$ dexamethasone. In Wtacha study', the incidence of pre-discharged emesis in $50 \mu \mathrm{g} / \mathrm{kg}$ ondansetron group was relatively higher (19\%) than in this study (13\%). That study ${ }^{9}$ demonstrated that, ondansetron as a sole prophylactic antiemetic in a dose of $50 \mu \mathrm{g} / \mathrm{kg}$ was more effective than either placebo or $10 \mu \mathrm{g} / \mathrm{kg}$ but not less effective than $100 \mu \mathrm{g} / \mathrm{kg}$ dose for control of PONV in a heterogeneous pediatric population. In that study, the effectiveness of 75 and $150 \mu \mathrm{g} / \mathrm{kg}$ ondansetron were not studied. Studies of blood levels after intravenous administration of ondansetron in healthy children during anesthesia have shown that a theoretical intravenous dose of $50 \mu \mathrm{g} / \mathrm{kg}$ ondansetron in a child will provide a similar area under the plasma concentration-time curve as a dose of $4 \mathrm{mg}$ which is the minimally effective antiemetic dose in adults ${ }^{21}$.

In the present study, the incidence of $24 \mathrm{~h}$ PONV in the placebo group (Dexamethasone pre-treated children) was 43\%. This incidence was in keeping with the result of Henzi and his colleagues ${ }^{\mathbf{1}}$. Several factors may have contributed to the low incidence of PONV observed in the placebo group of the present study. First is the preemptive use of dexamethasone, Second, the use of mivacuronium might have reduced the PONV in this study by allowing spontaneous recovery from the neuromuscular block without reversal of neuromuscular blockade with less incidence of PONV. Third, may be the propofolbased induction of anesthesia in older children. Barst and his colleagues ${ }^{22}$ reported a decreased from $55 \%$ to $21 \%$ in posttonsillectomy vomiting by utilizing a propofol-based anesthetic instead of gaseous agent and without utilizing antiemetic agents.

In the present study, the time to first postoperative analgesic, total analgesics consumptions, the need for rescue antiemetic (RAE), the fast tracking time (FTT), the time to first oral intake and parent's satisfaction score were recorded as clinically true outcome measures. These true clinical outcome measures were found to be significantly better in children who received $50 \mu \mathrm{g} / \mathrm{kg}$ ondansetron or more compared with those children who received placebo or $25 \mu \mathrm{g} / \mathrm{kg}$ ondansetron. Moreover, dexamethasone premedication was associated with improved oral intake after surgery. The unexpected readmissions to the hospital due to PONV as another clinically true outcome measure could not be assessed in this study because all of our patients were observed in the hospital for $24 \mathrm{~h}$ postoperatively.

Cost is increasingly a focus in health care $^{23}$. In the present study, $50 \mu \mathrm{g} / \mathrm{kg}$ ondansetron dose not only have the same efficacy of the higher doses on decreasing 
the incidence and severity of PONV, but it is less costly than the higher doses (75and $150 \mu \mathrm{g} / \mathrm{kg}$ ). In addition, the low dose $(50 \mu \mathrm{g} / \mathrm{kg})$ ondansetron was associated with lower nursing costs because of markedly less incidence of PONV, short FTT and less need for RAE.

In Conclusion, ondansetron $50 \mu \mathrm{g} / \mathrm{kg}$ IV is the minimum effective IV dose to decrease the incidence and severity of PONV in dexamethasone $(150 \mu \mathrm{g} / \mathrm{kg}$ IV) pretreated children undergoing adenotonsillectomy. This dose is associated with a significant reduction in the time to first postoperative analgesic, total analgesic consumptions, the need for rescue antiemetic (RAE), the time to first oral intake, the fast tracking time (FTT) and a higher parent's satisfaction scores. Increasing the dose of ondansetron to $150 \mu \mathrm{g} / \mathrm{kg}$ provides no significant benefits in reducing the incidence or severity of PONV after adenotonsillectomy.

\section{References}

1. Henzi I, Walder B, Tramer $\mathbf{R}$. Dexamethasone for the prevention of postoperative nausea and vomiting a quantitative systemic review. Anesth Analg, 2000; 90: 186-194.

2. Pappas AL, Sukhari R, Hotaling A J, Mikat-Stevens M. The effects of preoperative dexamethasone on the immediate and delayed postoperative morbidity in children undergoing adenotonsillectomy. Anesth Analg, 1998; 87: 57-61.

3. Splinter WM, Roberts DJ. Prophylaxis for vomiting by children after tonsillectomy: dexamethasone versus perphenazine. Anesth Analg, 1997; 85: 534-537.

4. Splinter WM, Roberts DJ. Dexamethasone decreases vomiting by children after tonsillectomy. Anesth Analg, 1996; 83: 913-915.

5. Tom L, Templeton J, Thompson M, Marsh RR. Dexamethasone in adenotonsillectomy. Int J Pediatr Otorhinolaryngol, 1996; 37: 115-120.

6. Aouad MT, Siddik SS, Rizk LB, Zaytoum GM. The effects of dexamethasone of postoperative vomiting after tonsilectomy. Anesth Analg, 2001; 92: 636640.

7. Subramaniam B, Madan R, Sadhasivam $\mathbf{S}$, et al. Dexamethasone is a cost effectivealternative to ondansetron in preventing PONV after pediatric strabismus repair: clinical investigation. Br J Anaesth, 2001; 86: 84-89.

8. Furs SR, Rodarte A. Prophylactic antiemetic treatment with ondansetron in children undergoing tonsillectomy. Anesthesiology, 1994; 81: 799-803.

9. Wtacha MF, Bras PJ, Cieslak GD, Pennant JH. The dose response relationship of ondansetron in preventing postoperative emesis in pediatric patients undergoing ambulatory surgery. Anesthesiology, 1995; 82: 47-52.

10. Rose JB, Brenn BR, Corddry DH, Thomas PC. Preoperative oral ondansetron for pediatric tonsillectomy. Anesth Analg, 1996; 82: 558-562.

11. Splinter WM, Rhine EJ. Prophylactic antiemetic in children undergoing tonsillectomy: high-dose vs. low-dose ondansetron. Pediatr Anesth, 1997; 7: 125-129.

12. Lopez-Olaondo L, Carrascosa F, Pueyo FJ. Combination of ondansetron and dexamethasone in the prophylaxis of postoperative nausea and vomiting. $\mathrm{Br} \mathrm{J}$ Anaesth, 1996; 76: 835-840.

13. Splinter WM, Rhine ED. Low-dose ondansetron with dexamethasone more effectively decreases vomiting after strabismus surgery in children than does high-dose ondansetron. Anesthesiology, 1998; 88: 72-75.

14. Tramer MR, Reynolds DJ, Moore RA, McQuay HJ. Efficacy, dose-response, and safety of ondansetron in prevention of postoperative nausea and vomiting: a quantitative systematic review of randomized placebo-controlled trials. Anesthesiology, 1997; 87: 1277-1289.

15. Aldrete JA. The post-anesthesia recovery score revisited. J Clin Anesth, 1995; 7: 8991.

16. Hirsch J. Impact of postoperative nausea and vomiting in the surgical setting Anaesthesia, 1994; 49 (suppl): 30-33.

17. Ferrari LR, Donlon JV. Metoclopramide reduces the incidence of vomiting after tonsillectomy in children. Anesth Analg, 1992; 75: 351.

18. Stene EN, Say RE, Younf LA, et al. Prospective, randomized double- blind, placebo controlled comparison metoclopramide and ondansetron for prevention of posttonsilectomy or adenotonsillectomy emesis. J Clin Anesth, 1996; 8: 540-4.

19. Litman RS, Wu CL, Catanzaro FA. Ondensatron decreases emesis after 
tonsillectomy in children. Anesth Analg, 1994; 78: 478-81.

20. Furst SA, Rodarte A. Prophylactic antiemetic treatment with ondansetron in children undergoing tonsillectomy. Anesthesiology, 1994; 81: 799-803.

21. Litman J, Spahr-Shopfer IA, Sikich N. Pharmacokinetics of intravenous ondansetron (5-HT3 antagonist) in healthy children. (Abstract) Can J Anaesthesia, 1993; 40: A24.
22. Barst SM, Markowitz A, Yossefy Y, et al. Propofol reduces the incidence of vomiting after tonsillectomy in children. Paediatr Anaesth, 1995; 5: 259-52.

23. Davis PJ, McGowan FX, Landsman I. Effect of antiemetic therapy on recovery and hospital discharge time: a double blind assessment of ondansetron, droperidol and placebo in pediatric patients undergoing ambulatory surgery. Paediatr Anaesth, 1995; 5: 342-46. 


\section{تحديد أقل جرعة وريدية مؤثرة من عقار الأوندانسترون لمنع القيء والغثيان بعد عملية استئصال اللوزتين واللحمية في الأطفال السابق الأقئ تحضريهم} قبل الجراحة بعقار الديكساميثازون

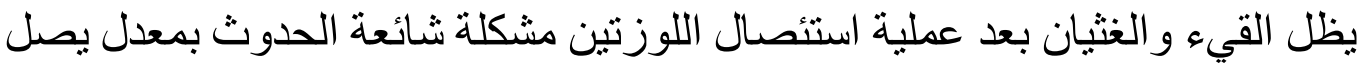

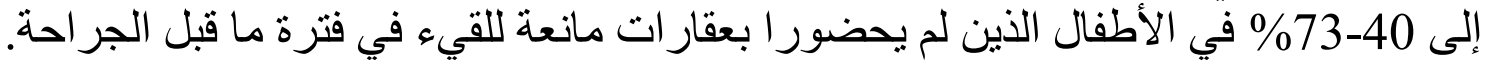

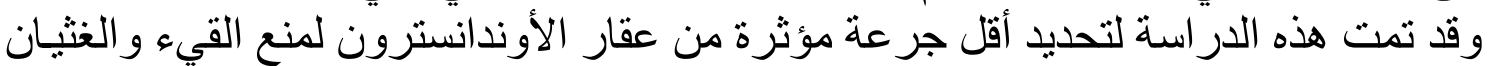

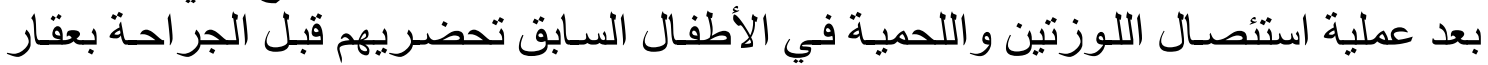
الايكساميثازون بمعدل 150 ميكروجر ام /كجم.

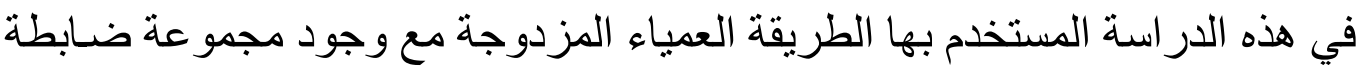

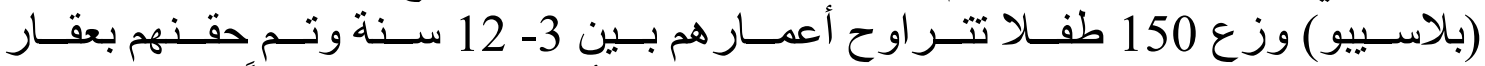

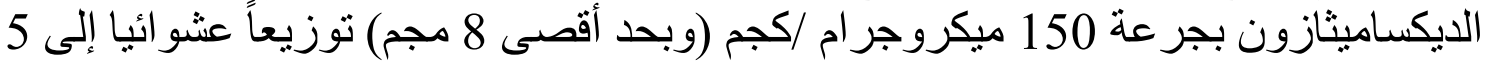

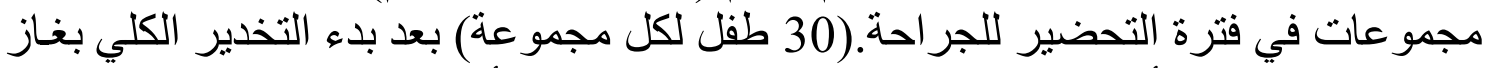

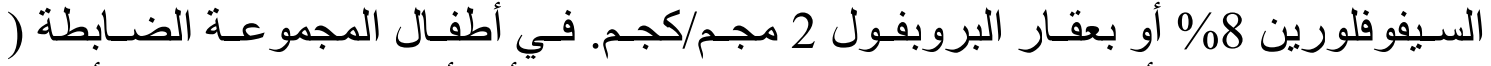

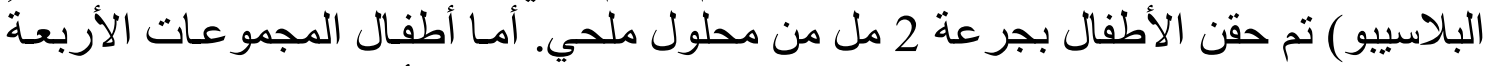

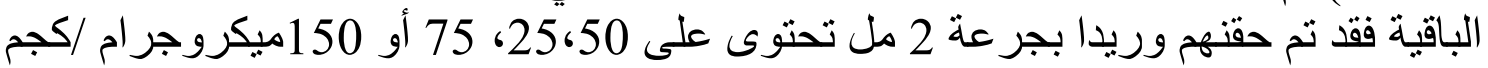

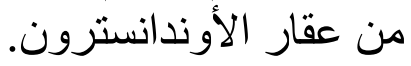

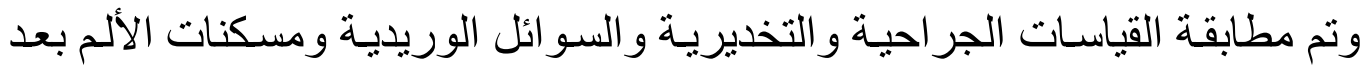

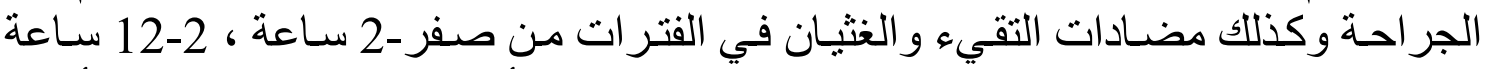

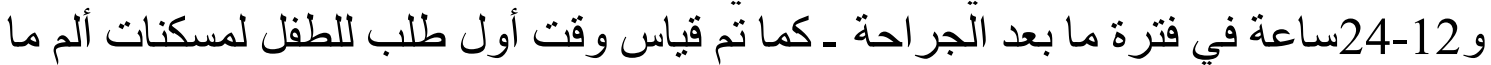

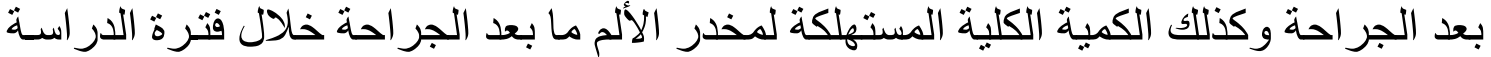

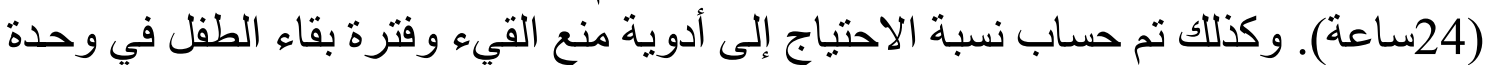

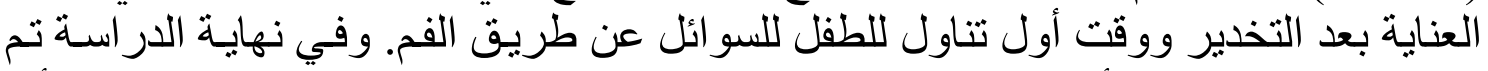

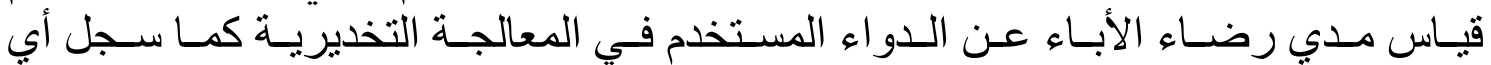
مضاعفات للاو اء.

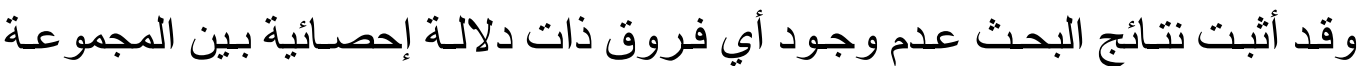

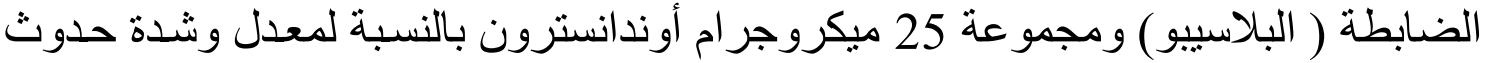

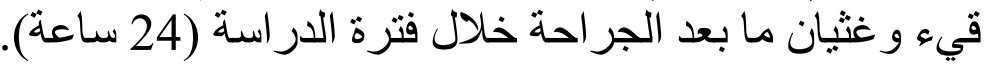

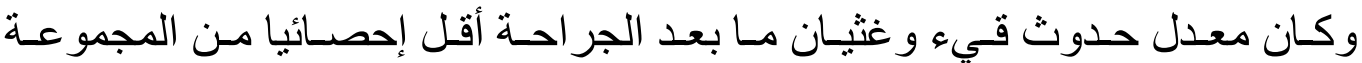

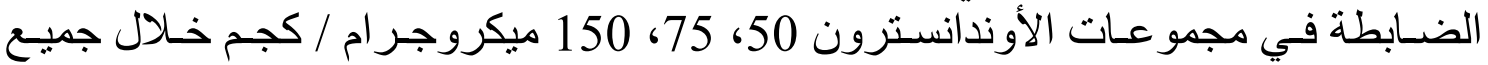

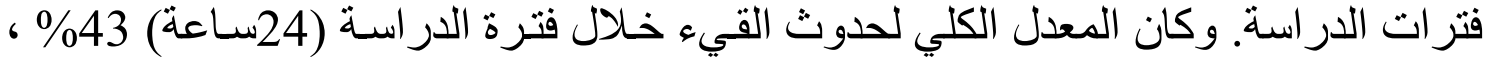

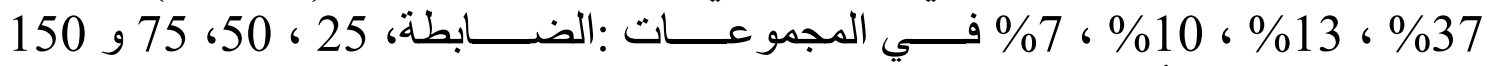

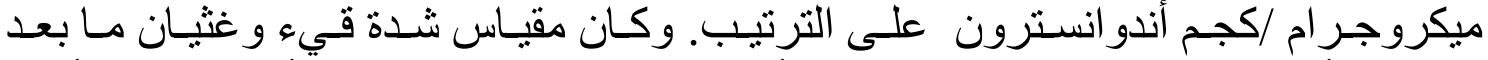

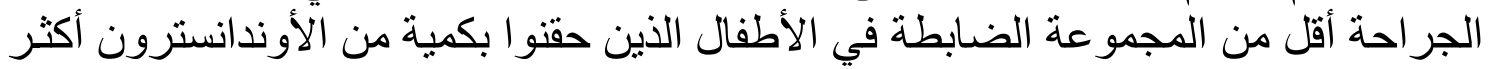

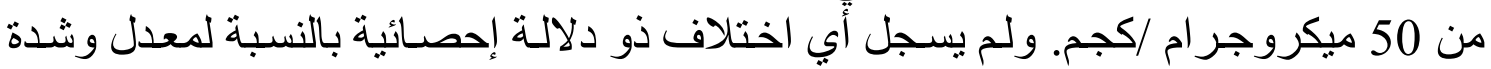


قيء و غثيان ما بعد لجر احة بين الأطفال الذين تناو لا جر عات أكثر من 50 ميكرو جرام / كجم من الأوندانسترون .

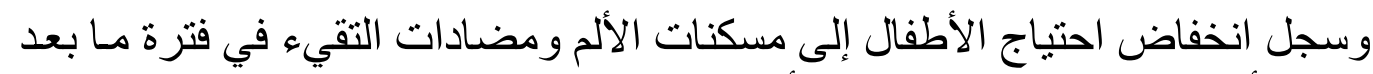

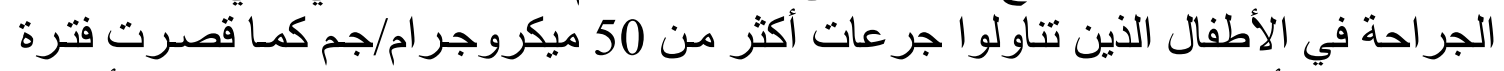

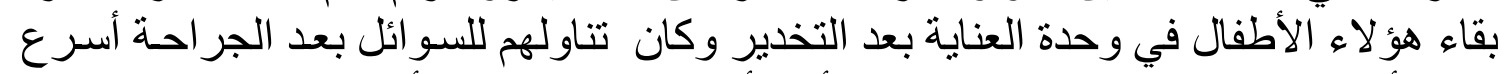

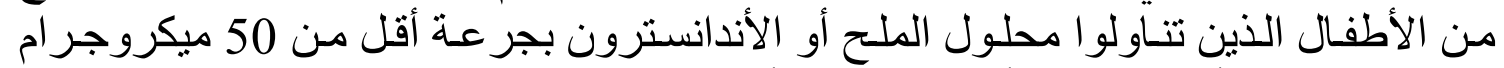

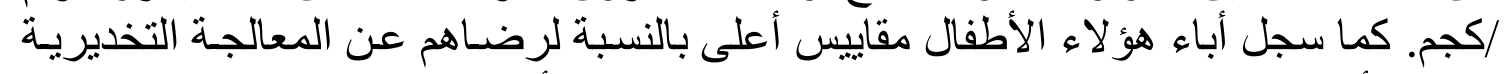

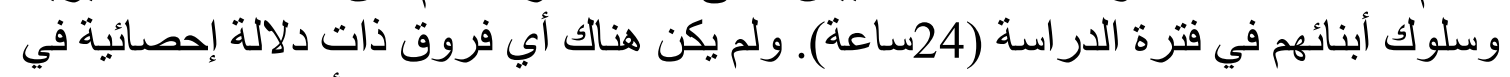

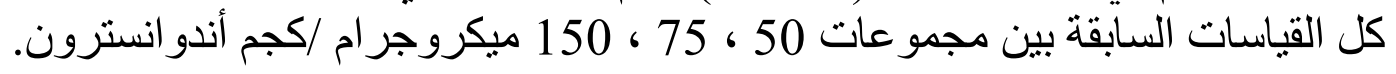

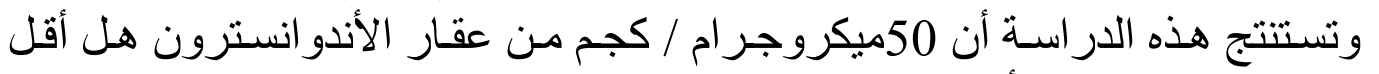

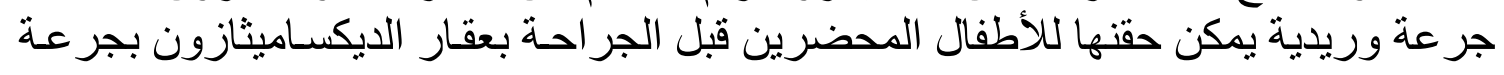

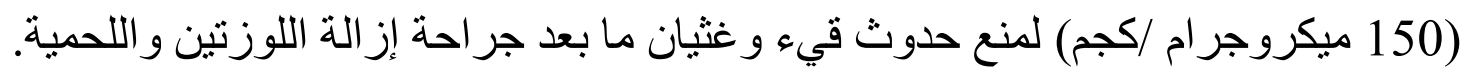

